\title{
Estimates of fluid intake, urine output and hydration-levels in women from
}

\section{Somaliland: a cross-sectional study}

\author{
Espen $H_{e e n}{ }^{*}$, Amal A. Yassin ${ }^{2}$, Ahmed A. Madar ${ }^{1}$ and Maria Romøren ${ }^{1}$ \\ ${ }^{1}$ Department of Community Medicine and Global Health, University of Oslo. P.O. box 1130, Blindern, 0318 Oslo, Norway \\ ${ }^{2}$ Department of Women's Health, Manhal hospital, Hargeisa, Somaliland
}

(Received 1 June 2021 - Accepted 16 July 2021)

Journal of Nutritional Science (2021), vol. 10, e66, page 1 of 10

doi:10.1017/jns.2021.54

Abstract

The study objective was to measure fluid intake and associations with background characteristics and hydration biomarkers in healthy, free-living, nonpregnant women aged 15-69 years from Hargeisa city. We also wanted to estimate the proportion of euhydrated participants and corresponding biomarker cut-off values. Data from 136 women, collected through diaries and questionnaires, $24 \mathrm{~h}$ urine samples and anthropometric measurements, were obtained with a cross-sectional, purposeful sampling from fifty-two school and health clusters, representing approximately 2250 women. The mean (95 \% CI) $24 \mathrm{~h}$ total fluid intake (TFI) for all women was $2.04(1.88,2 \cdot 20)$ litres. In multivariate regression with weight, age, parity and a chronic health problem, only weight remained a predictor $(P 0.034, B 0.0156(1 / \mathrm{kg}))$. Pure water, Somali tea and juice from powder and syrup represented $49 \cdot 3,24 \cdot 6$ and $11 \cdot 7 \%$ of TFI throughout the year, respectively. Mean $(95 \% \mathrm{CI}) 24 \mathrm{~h}$ urine volume (Uvol) was $1.28(1 \cdot 17,1 \cdot 39)$ litres. TFI correlated strongly with $24 \mathrm{~h}$ urine units $(r 0.67)$ and Uvol $(r 0.59)$. Approximately $40 \%$ of the women showed inadequate hydration, using a threshold of urine specific gravity (Usg) of $1 \cdot 013$ and urine colour (Ucol) of 4. Five percent had Usg > 1.020 and concomitant Ucol > 6, indicating dehydration. TFI lower cut-offs for euhydrated, nonbreast-feeding women were 1.77 litres and for breast-feeding, 2.13 litres. Euhydration cut-off for Uvol was 0.95 litre, equalling $9 \cdot 2$ urine units. With the knowledge of adverse health effects of habitual hypohydration, Somaliland women should be encouraged to a higher fluid intake.

Key words: 24-h urine volume: Beverages: Dehydration: Somaliland: Total fluid intake: Urine colour: Women

\section{Introduction}

Adequate hydration is paramount for health and well-being, and bodily fluid balance is a fine-tuning between water loss and total water intake (TWI). Water losses through sweat, faeces, perspiration and urine are determined by environment temperature and humidity, as well as the size, activity level and nutrient intake of the individual. Proteins and inorganic salts in the diet affect the total renal solute load and subsequently the amount of water needed to excrete these osmotic active substances and maintain homeostasis ${ }^{(1,2)}$.

TWI is the sum of water content in beverages, including plain water, food moisture and metabolic water. Since the latter two are difficult to measure, the sum of beverages as total fluid intake (TFI) might be a good proxy in free-living individuals. TFI equals $62-80 \%$ of TWI, depending on culture and cuisine, and the two variables are highly correlated $(r 0.96)$ in several studies ${ }^{(3-8)}$. Established guidelines from the USA and Europe have described adequate TWI of 2.7 and 2.0 litres, respectively, and corresponding TFI of 2.2 and 1.6 litres, as necessary for ensuring adequate hydration in adult females living in temperate climate with sedentary activity level. Lactating women should increase their fluid intake by $0 \cdot 6$ $1 \cdot 1$ litres, proportional to breast milk production ${ }^{(9-11)}$. The validity of universal guidelines, even at the population level, is questioned with so many factors impacting fluid balance ${ }^{(1)}$.

* Corresponding author: Espen Heen, email: e.k.heen@medisin.uio.no

Abbreviations: BFQ: beverage frequency questionnaire; $\mathrm{MCH}$ : mother-child health clinics; PWI: plain water intake; TFI: total fluid intake; TWI: total water intake; Ucol: urine colour; Uosm: urine osmolality; Usg: urine specific gravity; Uvol: urine volume 
There are currently no international guidelines for hot climate countries.

Adequate hydration is described by a urine osmolality (Uosm) between the minimal and maximal concentrating capacity of the kidney, at the population level, approximately $50-800 \mathrm{mOsmol} / \mathrm{kg}^{(1,2,12)}$. Rising plasma osmolality beyond normo-physiological fluctuations in the range of 285-295 $\mathrm{mOsmol} / \mathrm{kg}$ defines dehydration, a similar fall implies overhydration $^{(12)}$. Consequently, using a urine concentration of 800 $\mathrm{mOsmol} / \mathrm{kg}$ as a cut-off for dehydration is common, with a corresponding urine specific gravity (Usg) $>1.020$ and a urine colour $(\mathrm{Ucol}) \geq 7^{(1,13-16)}$. Adequate hydration can be further subdivided: In optimal euhydration, no active waterconserving happens. Recently, suggested cut-offs are Usg < 1.013 and Ucol $<4$ to detect Uosm $<500 \mathrm{mOsmol} / \mathrm{kg}$ with high specificity and sensitivity ${ }^{(12,17)}$. Hypohydration, on the other hand, is defined as a 'steady-state condition of reduced total body water' with a regular increase in the kidney reabsorption of water ${ }^{(5)}$. Hypohydration and habitual low TFI are a common finding in the published literature and correlates in several studies ${ }^{(18)}$. Habitual low TFI and, especially, low plain water intake (PWI) are associated with increased risk of urinary tract infection, chronic kidney disease, recurrent kidney stones and poor glycaemic regulation, including increasing HbA1C and type 2 diabetes. Although no causation is established, the cardio-metabolic effects could theoretically be mediated through higher average circulating concentrations of vasopressin and cortisol ${ }^{(5,12,14,18,19)}$. An additional decline in physical and cognitive performance and impaired gastrointestinal, thermoregulatory, hemodynamic and renal functions are found in chronic dehydration ${ }^{(20,21)}$.

Little is known about female fluid intake and hydration in lowand lower-middle-income countries (LLMIC), particularly in hot and dry environments and in cultures distinct from Western lifestyles, such as Somaliland ${ }^{(7)}$. This is a paradox since heat, drought, high fertility, gender inequity and unhealthy sociocultural traditions, combined with restricted water availability and quality, increase the risk of poor hydration. In Somaliland, voiding problems due to female genital cutting and limited access to decent public toilets may impact how much women drink during the day ${ }^{(22)}$. High mineral content in local groundwater poses an additional risk of increased renal solute load and less free water reserve for hydration regulation. Kidney stones are reported to be more prevalent in certain regions of the country ${ }^{(23,24)}$. To propose measures for optimising fluid intake of women in Somaliland, the aims of the present study were as follows:

(1) To describe the use and feasibility of novel fluid intake and voiding data collection tools tailored for LLMIC.

(2) To measure the fluid intake and urine volume (Uvol) of healthy, non-pregnant women from Hargeisa city in Somaliland, aged 15-69 years and associations with background characteristics and hydration biomarkers clinically available in this context.

(3) To estimate the proportions and corresponding biomarker cut-off values of dehydrated, hypohydrated and euhydrated participants.
Method

\section{Setting, study design and recruitment}

We recruited non-pregnant women from the capital city Hargeisa, which harbours approximately $25 \%$ of the two million female inhabitants in the country. The sampling frame was NAGAAD (https://nagaad.org/), a network of women empowering organisations (local non-governmental organisation, (LNGOs)), offering various activities such as literacy training in internally displaced people's camps to women rights groups for university students. From fifty different women groups, representing approximately 2200 women, five almost equally sized groups were purposefully selected, with the goal of capturing the range of age, socio-economic status (SES), education and living location within the city as described by the randomised female urban Somaliland Multi Indicator Cluster Survey sample ${ }^{(25)}$. In addition, breast-feeding women were recruited consecutively from two of the fourteen mother-child health clinics $(\mathrm{MCH})$ in the city, since they were underrepresented in NAGAAD.

\section{Inclusion of participants}

The inclusion of each woman was contingent on habitual fluid/food intake; normal fluid and energy metabolism/balance; urine collection ability and record/recall competency (detailed exclusion criteria in Supplementary Table S1). Receipts, medicine containers or medicines confirmed drug use.

\section{Data collection}

A structured oral questionnaire in English was developed with items from pre-existing, well-tested questionnaires ${ }^{(26-29)}$. Two native-speaking, bilingual English/Somali health workers provided parallel translations into Somali. Background data on health and reproductive history, SES, household and eating habits were obtained in oral Somali.

Weight (in between meals) was measured at $0 \cdot 1 \mathrm{~kg}$ precision (Seca 874 and 813 ) and height to the nearest $0 \cdot 1 \mathrm{~cm}$ (Seca 217) with the women standing barefoot, covered in a standard underdress (dirac) and a light head cover (shalmad), details as described elsewhere ${ }^{(30)}$.

Fluid intake and voiding frequency/volumes during a $24 \mathrm{~h}$ trial were obtained through four interconnected methods (1-4). A detailed explanation of the methods and tools in use is found in the Supplementary material. Since general diet recall questionnaires have a tendency to underestimate TFI, a fluid specific diary and a beverage frequency questionnaire (BFQ) were developed and piloted with illiterate women ${ }^{(31)}$ :

(1) Illiterate women used a $24 \mathrm{~h}$ box-diary - a small box with coloured paper symbols that helped the women log number and volumes of beverages and voids during the trial. Literate women used a similar symbol-diary with six-time intervals covering $24 \mathrm{~h}$.

(2) In a $24 \mathrm{~h}$ recall interview, the diaries were investigated and the data systematised. The sum of beverage frequency and 
volumes became TFI, and the sum of voiding frequency with corresponding magnitude (small $=1$, medium $=2$, large $=3$ ) became ' $24 \mathrm{~h}$ urine units'.

(3) The BFQ investigated how often women were drinking plain water (fifteen types or sources), hot drinks (four types), milk and dairy products (six types), juices (four types) and soft drinks during the last 12 months. A semiquantitative number of servings of each fluid type were recorded with the alternatives: never or less than one time per month, one to three times per month, one time per week, two to three times per week, four to six times per week, one time per day, two to three times per day, four to six times per day, more than seven times per day. This provided data for daily TFI averaged across a year (yearTFI).

(4) After voiding at time zero, the women started to collect urine through the day and night and did a final void collection at the place of interview exactly $24 \mathrm{~h}$ later. The women were asked about urine spillage or bottle leakage, and missed voids were registered. Fruit and vegetable intake during the $24 \mathrm{~h}$ were assessed.

\section{Field work}

Nine bilingual female nurses from Hargeisa were trained in research ethics and survey methodology and evaluated in use of the exclusion criteria, the questionnaire, the fluid intake and voiding diaries, anthropometry and volume measurements. Inter-assessor agreement showed fair reliability in accordance with 'Anthropometric measurement error and the assessment of nutritional status ${ }^{(32)}$. The research assistants piloted the $24 \mathrm{~h}$ trial.

The field work happened in May and June 2011 in close collaboration with leaders and teachers for each $\mathrm{LNGO} / \mathrm{MCH}$ group. The superiors made the women feel secure and ensured good compliance. De-briefing and discussion with the whole research team were done regularly in order to improve performance.

The women were individually trained to use the tools and their competency verified. During the $24 \mathrm{~h}$ trial, a nurse contacted the women once to strengthen compliance and was available for sorting out problems. The $24 \mathrm{~h}$ trials started out on Sundays (44\%); Mondays (8\%) and Tuesdays (48\%), not coinciding with Muslim festivals.

\section{Laboratory analysis}

The incoming temperature of the urine was between 12 and $18^{\circ} \mathrm{C}$. All measurements were done by two assessors. The urine samples were screened with a human chorionic gonadotropin test. Uvol was measured by a dietary scale (Seca Culina) at $1 \mathrm{~g}$ precision. Ucol was assessed visually by a chart displaying eight different dilutions, light straw-yellow being 1 and dark green-brown 8 . The colour chart had been validated and found suitable as a hydration biomarker tool for women in all reproductive states ${ }^{(11,33)}$. With a paper-white wall of $0.5 \mathrm{~m}$ behind, light from above (four 20 watt fluorescent tubes, Comet FL 20D, white, Indonesia) was passing through
$30-50 \mathrm{ml}$ urine in an ordinary water bottle (Durdur $750 \mathrm{ml}$ bottle, local brand) and in a clear, small plastic cup (Party TechPak $200 \mathrm{ml})$. The colour chart was placed adjacent to the longest way of light horizontally through the bottle and cup. The average of four readings was recorded. A urinalysis strip (Insight Xpert, 10SW Reagent strip, Acon laboratories) provided grading for glucose, protein, $\mathrm{pH}$ and Usg by visual inspection in accordance with the 'directions for use', details in Supplementary Table S2. All strips were read in the same light conditions.

\section{Statistics}

Sample size was guided by Uvol with a standard deviation (SD) of approximately $400 \mathrm{ml}^{(34)}$. A design effect of 1.5 for the clusters and a clinical precision of $\pm 100 \mathrm{ml}$ were set and provided a sample size of ninety-two. Including possible skewed distribution, dropouts and post-trial exclusions, we aimed for a total enrolment of 150 women.

Missing, conflicting or irregular data were investigated with the research participants. Double data entry error (Epidata Entry version 3.1 ) was $0 \cdot 26 \%$ before corrections. Data analyses were done with Epidata Analysis version 2.2 and IBM SPSS version 26.

Uvol was calculated as urine weight/Usg. Data from the full year $\mathrm{BFQ}$ were all recoded into frequencies per day and mean daily volumes estimated (yearTFI).

Distributions were inspected visually and assessed with skewness and kurtosis, tests of normality and outlier checks. Clustering effects for key outcome variables were generally small (intraclass correlation coefficient $<10 \%$ ) and nonsignificant when assessed with a linear mixed 0 -model, only including the intercept with the clusters as a random variable. The data have been treated as non-clustered.

For group sample sizes of $>30$, means were compared with the independent-samples $t$-test, adjusted for unequal variances. For more than two comparisons, one-way ANOVA with post hoc Tuckey's test was used. The nonparametric Mann-Whitney $U$ test or, for more than two samples, the Kruskal-Wallis test was used with non-normal distributions of the differences. Categorical data were compared with Pearson's $\chi^{2}$ test or Fisher's exact test.

In Pearson's product-moment correlation, we used square root and $\log _{10}$ transformations to ensure best fit to normality, meeting assumptions of linear relationships and homoscedasticity. Usg and Ucol were analysed with Spearman's rank-order correlation $(\rho)$. Univariate and multivariate regression honoured the assumptions of linearity, no co-linearity, and independence, normality and homoscedasticity of residuals. The significance level $(\alpha)$ was $0 \cdot 05$.

\section{Ethics}

Research permission from the Ministry of Health in Somaliland (No. MOH/3c11.00/2011) was granted on 11 January 2011. Ethical clearance was given by the Norwegian Regional Ethical Committee (No. 2010/1905 REK Sør-Øst) on 15 September 2010 and extended until 2022. 
Information was given orally and in writing with special emphasis on the voluntary character of participation and the possibility of withdrawal at any time during the study without any consequences. Oral consent was observed by a third party often a leader from her LNGO - and signed. Discretion and confidentiality were a priority during the interviews and trial. The participants received counselling on medical issues. Possible pathology, like diabetes or kidney disease, was acted on by offering the women further investigations and a 3 month treatment free of charge. A gift of 10 dollars value was given.

The ethical aspects of the study were guided by 'the WMA Declaration of Helsinki 2008'; 'UNESCO, IBC on Consent, 2008'; 'Nuffield Council on Bioethics "Research in Developing Countries 2002'" and the 'CIOMS International Guidelines for Biomedical Research (2002) and Epidemiological Studies (2008)'.

\section{Results}

The pre-selected groups contained 160 women. After exclusion, 127 women (15-69 years) completed the study, a participation ratio of $79 \%$ (Fig. 1). There were no dropouts or exclusions above 50 years of age.

Background characteristics are described in Table 1. A chronic health problem other than the exclusion criteria was reported by $46 \%$. There was a spread in the number of births from 0 to $18,23 \%$ were breast-feeding and $41 \%$ were never married and nulliparous. The median age of breast-feeding children was 5 months (range 0-20), the majority fed four to eight times $(22 \%)$ or more than eight times $(70 \%)$ per day. In total, $97 \%$ of the women used their memo-tool according to the instructions. Change from normal routine was reported by $10 \%$. Through the $13 \mathrm{~d}$ of trials, the mean (min.-max.) $24 \mathrm{~h}$ temperature was 25 (24$\left.26^{\circ} \mathrm{C}\right)$, and the relative humidity was 58 (52-65\%).

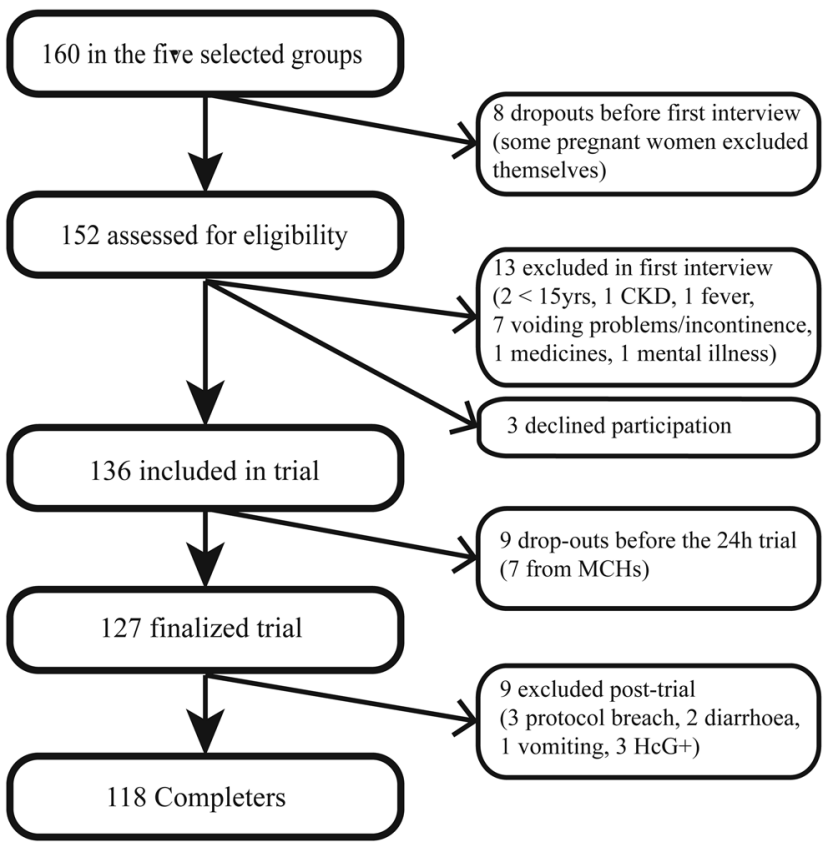

Fig. 1. Recruitment outcome with dropouts, declined and excluded from analyses.
Table 1. Background characteristics of 118 women from Hargeisa city

\begin{tabular}{lrr}
\hline & Mean & SD \\
\hline Age (years) & 30.2 & 12.6 \\
Weight $(\mathrm{kg})$ & 60.4 & $13 \cdot 6$ \\
Height $(\mathrm{cm})$ & 161.1 & $5 \cdot 8$ \\
Household size $(n)$ & $8 \cdot 6$ & $3 \cdot 1$ \\
Children 0-14 years in house $(n)$ & 3.3 & 2.3
\end{tabular}

\begin{tabular}{lcc}
\hline & Median & IQR \\
\hline Number of childbirths & 2.5 & $0-8$
\end{tabular}

\begin{tabular}{|c|c|c|}
\hline & $\%$ & $n$ \\
\hline$<22$ years & $37 \cdot 3$ & 44 \\
\hline 22-34 years & $29 \cdot 7$ & 35 \\
\hline$\geq 35$ years & $33 \cdot 1$ & 39 \\
\hline $\mathrm{BMI}<18.5$ & $16 \cdot 1$ & 19 \\
\hline BMI 18.5-24.99 & $48 \cdot 3$ & 57 \\
\hline BMI 25.0-29.99 & $27 \cdot 1$ & 32 \\
\hline $\mathrm{BMI}<30 \cdot 0$ & 8.5 & 10 \\
\hline Chronic health problem & $45 \cdot 8$ & 54 \\
\hline One or two meals in the trial & $12 \cdot 7$ & 15 \\
\hline Three or more meals in the trial & $87 \cdot 3$ & 103 \\
\hline Never attended school ${ }^{\mathrm{a}}$ & $48 \cdot 3$ & 57 \\
\hline Divorced/widowed & 8.5 & 10 \\
\hline Single & $40 \cdot 7$ & 48 \\
\hline Married & $50 \cdot 8$ & 60 \\
\hline Man head of household & $69 \cdot 5$ & 82 \\
\hline Ahmed Dhagax district & $20 \cdot 3$ & 24 \\
\hline M. Hayb/M Mooge distr. & $29 \cdot 7$ & 35 \\
\hline Gacan Libaax distr. & 0.0 & 0 \\
\hline 26th June distr. & $13 \cdot 6$ & 16 \\
\hline Ibrahim Koodbuur distr. & $36 \cdot 4$ & 43 \\
\hline Hut & $27 \cdot 1$ & 32 \\
\hline Iron sheet house & 31.4 & 37 \\
\hline Cement/brick/stonehouse & 41.5 & 49 \\
\hline Electricity in house & 47.5 & 56 \\
\hline Total & $100 \cdot 0$ & 118 \\
\hline
\end{tabular}

IQR, Inter quartile range.

${ }^{\text {a }}$ Minimum schooling defined as a 6 month full-time course or a successful literacy course.

Supplementary Table S3 describes background characteristics of the various subgroups with $P$-values of group differences. The declining, dropped out and excluded women were not significantly different from the completers.

\section{Fluid intake}

The median (interquartile range (IQR)) TFI of the women during the trial was $1.87(1.22)$ litres. We found significantly different mean TFI for age, a chronic health problem and parity (dichotomous) (Table 2). SES variables, like school inclusion, completed educational level or housing standard, were not associated with TFI. In univariate regression, weight predicted TFI $\left(F 18 \cdot 24, P<0 \cdot 005\right.$, adjusted $\left.R^{2} 0 \cdot 13\right)$ with a positive slope $(B \quad 0.0242, P<0.005)$, indicating a $24 \mathrm{ml}$ increase per $\mathrm{kg}$ bodyweight. BMI was also a positive predictor with an adjusted $R^{2}$ of $0 \cdot 12$. In multivariate regression (adjusted $R^{2} 0 \cdot 14$, ANOVA: $\left.4,5 \cdot 62, P<0 \cdot 0005\right)$ with the significant univariate predictors, only intercept $[B(95 \% \mathrm{CI}) 0.79(0.41$, 1.53) litres, $P$ 0.04] and weight remained significant $[B$ (95 $\%$ CI $16(12,30) \mathrm{ml}, P$ 0.034]. 
Table 2. Subgroup comparison of mean TFI and Uvol during $24 \mathrm{~h}, 118$ women in Hargeisa

\begin{tabular}{|c|c|c|c|c|c|c|c|}
\hline & \multirow[b]{2}{*}{$n$} & \multicolumn{3}{|c|}{ TFI (litres) } & \multicolumn{3}{|c|}{ Uvol (litres) } \\
\hline & & Mean & $95 \% \mathrm{Cl}$ & $P$-value & Mean & $95 \% \mathrm{Cl}$ & $P$-value \\
\hline All & 118 & $2 \cdot 04$ & $1 \cdot 88-2 \cdot 20$ & & $1 \cdot 28$ & $1 \cdot 17-1 \cdot 39$ & \\
\hline$<22$ years & 44 & $1 \cdot 83^{*}$ & $1 \cdot 60-2 \cdot 06$ & 0.022 & $1 \cdot 22$ & $1.05-1.40$ & 0.577 \\
\hline 22-34 years & 35 & 1.95 & $1 \cdot 66-2 \cdot 24$ & & $1 \cdot 26$ & $1.08-1.44$ & \\
\hline$\geq 35$ years & 39 & $2 \cdot 35^{\star}$ & $2 \cdot 02-2 \cdot 68$ & & $1 \cdot 36$ & $1 \cdot 13-1.59$ & \\
\hline LNGO & 94 & 1.96 & $1 \cdot 79-2 \cdot 14$ & 0.063 & $1 \cdot 21$ & $1.09-1.33$ & 0.010 \\
\hline $\mathrm{MCH}$ & 24 & $2 \cdot 34$ & $1 \cdot 92-2 \cdot 76$ & & $1 \cdot 56$ & $1 \cdot 27-1 \cdot 85$ & \\
\hline Chronic health problem & 54 & $2 \cdot 26$ & $1.98-2.55$ & 0.014 & 1.37 & $1.17-1.56$ & 0.161 \\
\hline None & 64 & $1 \cdot 85$ & $1.67-2.03$ & & $1 \cdot 21$ & $1 \cdot 08-1.33$ & \\
\hline Nulliparous & 48 & 1.69 & $1.51-1.88$ & $<0.005$ & $1 \cdot 12$ & $0.99-1.25$ & 0.009 \\
\hline Parous & 70 & $2 \cdot 28$ & $2 \cdot 05-2 \cdot 51$ & & $1 \cdot 39$ & $1 \cdot 23-1.55$ & \\
\hline Breast-feeding & 27 & $2 \cdot 29$ & $1.90-2 \cdot 67$ & $0 \cdot 113$ & 1.46 & $1 \cdot 18-1 \cdot 74$ & 0.143 \\
\hline Non-breast-feeding & 90 & 1.98 & $1 \cdot 80-2 \cdot 16$ & & $1 \cdot 24$ & $1 \cdot 12-1 \cdot 36$ & \\
\hline Primary/secondary school & 15 & $2 \cdot 24$ & $1 \cdot 64-2 \cdot 84$ & 0.352 & $1 \cdot 35$ & $0.97-1.73$ & 0.636 \\
\hline Informal $^{\mathrm{a}}$ schooling & 103 & $2 \cdot 01$ & $1 \cdot 83-2 \cdot 18$ & & $1 \cdot 27$ & $1 \cdot 15-1 \cdot 39$ & \\
\hline Nomadic hut & 32 & $2 \cdot 03$ & $1.66-2.40$ & 0.807 & & & \\
\hline Iron sheets house & 37 & 1.97 & $1 \cdot 72-2 \cdot 22$ & & & & \\
\hline Cement/bricks/stone house & 49 & $2 \cdot 1$ & $1 \cdot 83-2 \cdot 36$ & & & & \\
\hline
\end{tabular}

${ }^{a}$ Koranic and adult literacy.

* Significant difference in a post hoc test.

For all types of beverages, an all-year mean (SD) of 8.1 (3.17) servings per day was found. Pure water, Somali tea and juice from powder or syrup represented $49 \cdot 3,24.6$ and $11.7 \%$ of yearTFI, respectively. Local drinking water made up $89.6 \%$ of all servings with a mean of 1.83 litres/d. Mean intake of all other beverages totalled $0 \cdot 21$ litre with large individual differences and skewed distributions (Table 3). Public tap water and water from tanker trucks, providing deep or shallow groundwater, respectively, were used by $95.0 \%$ of the women, while rainwater was the main source in $2.5 \%$. Practically, all had the same water sources for drinking and cooking (99.2\%). Drinking water was treated by $10 \cdot 0 \%$. The water source supply was described as reliable or most reliable in $95.8 \%$ of completers. We found a moderate positive Spearman's correlation of $0.46(P<0.005)$ between TFI and yearTFI.

Urine

Looking at the temporal precision in $24 \mathrm{~h}$ urine collection, $93 \%$ were within the range of -7 to +8 min. Compared with crude Uvol, adjustments for collection duration and the number of missed urine units (voids) during the trial changed mean and median upwards 1.51 and $1.41 \%$, respectively.

Median (IQR) Uvol was $1.16(0 \cdot 86,1.59)$ litres. We found significantly different mean Uvol for parity, but not for age (Table 2). Two urine samples were red-tinged, but not due

Table 3. Estimated ${ }^{a}$ mean daily beverage intake (yearTFI) in $\mathrm{ml}$ derived from the BFQ, 118 women in Hargeisa

\begin{tabular}{|c|c|c|c|c|c|c|c|c|c|}
\hline & & P05 & P25 & P50 & P75 & P95 & Mean & Groupmean & $\%$ \\
\hline \multirow[t]{8}{*}{ Local water } & Household water, local sources & 4 & 630 & 630 & 1260 & 1890 & 957 & 1830 & $89 \cdot 6$ \\
\hline & Somali tea & 4 & 252 & 630 & 630 & 1260 & 497 & & \\
\hline & Other types of tea & 1 & 1 & 1 & 1 & 1 & 3 & & \\
\hline & Coffee & 4 & 4 & 4 & 17 & 36 & 14 & & \\
\hline & Soup & 4 & 4 & 17 & 36 & 90 & 35 & & \\
\hline & Powder milk & 1 & 1 & 1 & 36 & 630 & 78 & & \\
\hline & Juice from powder or syrup & 4 & 36 & 252 & 252 & 630 & 239 & & \\
\hline & Grain porridge & 0 & 0 & 0 & 0 & 2 & 7 & & \\
\hline \multirow[t]{4}{*}{ Manufactured beverages } & Bottled water & 4 & 4 & 4 & 17 & 252 & 41 & 92 & 4.5 \\
\hline & Soft drinks & 2 & 2 & 2 & 2 & 36 & 14 & & \\
\hline & Long-life milk & 1 & 1 & 1 & 1 & 36 & 13 & & \\
\hline & Imported juice & 4 & 4 & 4 & 17 & 180 & 25 & & \\
\hline \multirow[t]{4}{*}{ Local dairy products } & Local fresh cow's milk & 4 & 4 & 4 & 17 & 252 & 43 & 77 & 3.8 \\
\hline & Local fresh goat's milk & 2 & 2 & 2 & 2 & 18 & 11 & & \\
\hline & Local fresh camel's milk & 4 & 4 & 4 & 4 & 18 & 11 & & \\
\hline & Local fresh yogurt & 4 & 4 & 4 & 4 & 36 & 12 & & \\
\hline \multirow[t]{2}{*}{ Local juice } & Fresh orange juice & 2 & 2 & 2 & 2 & 90 & 18 & 42 & $2 \cdot 1$ \\
\hline & Other types of fresh juice & 4 & 4 & 4 & 17 & 180 & 25 & & \\
\hline Total & & 870 & 1424 & 1965 & 2501 & 3737 & 2042 & & 100 \\
\hline
\end{tabular}

$P$, Percentiles.

${ }^{a}$ Assuming that mean fluid intake and the size of drinking containers in the trial and the full year are the same, resulting in an average container volume of $252 \mathrm{ml}$. 
to beetroot, the only consumed vegetable known to affect Ucol. One woman had $1+$ on protein, none had glycosuria and seven had urine with $\mathrm{pH} 7$, the rest $\mathrm{pH} 5$ and 6 .

\section{Correlation between fluid intake and urine hydration biomarkers}

We found strong positive linear correlations between TFI and urine volume variables and negative medium correlations of TFI with Ucol and Usg (Table 4). A sensitivity analysis, only including participants with all voids collected, did not improve the correlation coefficients significantly (not shown). The strongest linear predictor for TFI and Uvol, explaining 45 and $75 \%$ of the variability, respectively, was $24 \mathrm{~h}$ urine units. Uvol regressed on $24 \mathrm{~h}$ urine units ( $F$ 372, $P<0.0005)$ provided the equation $(95 \% \mathrm{CI})$ : $\mathrm{Uvol}=0.124$ $(0 \cdot 11,0 \cdot 14) \times$ urine units $-0 \cdot 055$ litre, with intercept not statistically significant from 0 . Among the urine concentration variables, Ucol had the highest explanatory values with $14 \%$ for TFI and $65 \%$ for Uvol.

\section{Relative index of hydration}

The strong correlation between the urine hydration variables provided support for a multi-biomarker hydration analysis. Placing the women in seven percentile groups based on increasing Uvol, we calculated the mean values for all groups in order to compare the different hydration variables. Even with group numbers as low as $n 10$, the high correlation and relatively low SD within each group ensured increasing mean values from group 1 to group 7, with one exception within TFI (Supplementary Table S4 of Supplementary material). Mean values were converted to lower cut-offs by finding the midpoint between adjacent means. Table 5 displays these values for different levels of hydration in university women from the USA (Ref.), compared with our Somaliland sample ${ }^{(4)}$. Using a threshold of approximately $500 \mathrm{mOsmol} / \mathrm{kg}$, equal to Usg $<1.013$ and $\mathrm{Ucol}<4$ as euhydration limits, the four highest Somaliland percentile groups (4-7) are euhydrated, approximating $60 \%$ of the women. A sensitivity analysis excluding urine with $\mathrm{pH} 7$ did not alter the proportions. Dehydrated women were found in the $9 \%$ with the most concentrated urine: $5 \%$ had Usg $>1.020$ and concomitant $\mathrm{Ucol}>6$.

TFI lower cut-offs for euhydrated, non-breast-feeding and breast-feeding women in this study, using the 40-60 percentile group, are 1.77 and 2.13 litres, respectively. Similarly, plain TFI 40 percentile cut-offs are 1.55 and 2.07 litres, and yearTFI 1.62 and 2.27 litres, respectively (Fig. 2). Euhydration cut-off for Uvol is 0.95 litre, equalling 9.2 urine units.

\section{Discussion}

This is the first study describing details of fluid intake and hydration biomarkers in healthy, free-living African women, expanding the understanding of female fluid turnover in a global context. We have shown that such a study is feasible with new data collection tools developed and piloted to ensure that illiterate women are able to provide credible information about their drinking and voiding habits. The study monitored the

Table 4. Correlation coefficients matrix of fluid intake, urine volume and hydration biomarkers in 116 women

\begin{tabular}{|c|c|c|c|c|c|c|c|}
\hline & & TFI & yearTFI & $24 \mathrm{~h}$ urine units & Uvol & Ucol & Usg \\
\hline TFI & Pearson's $r$ & 1 & $0.489^{* *}$ & $0.670^{* *}$ & $0.593^{\star \star}$ & $-0.368^{\star \star}$ & $-0.270^{*}$ \\
\hline yearTFI & Pearson's $r$ & $0.489^{* *}$ & 1 & $0.385^{\star *}$ & $0.272^{\star *}$ & -0.093 & -0.034 \\
\hline $24 \mathrm{~h}$ urine units & Pearson's $r$ & $0.670^{* *}$ & $0.385^{* *}$ & 1 & $0.868^{* *}$ & $-0.646^{\star *}$ & $-0.487^{\star *}$ \\
\hline Uvol & Pearson's $r$ & $0.593^{\star \star}$ & $0.272^{\star \star}$ & $0.868^{\star *}$ & 1 & $-0.809^{\star *}$ & $-0.694^{\star *}$ \\
\hline Ucol & Spearman's $\rho$ & $-0.368^{\star \star}$ & -0.093 & $-0.646^{\star \star}$ & $-0.809^{\star *}$ & 1 & $0.746^{\star *}$ \\
\hline \multirow[t]{2}{*}{ Usg } & Spearman's $\rho$ & $-0.270^{\star}$ & -0.034 & $-0.487^{\star *}$ & $-0.694^{\star \star}$ & $0.746^{\star *}$ & 1 \\
\hline & $n$ & 116 & 116 & 116 & 116 & 115 & 88 \\
\hline
\end{tabular}

Correlations $>0.50$ : darker colour indicates stronger correlation.

${ }^{* *}$ Correlation is significant at the 0.001 level (two-tailed).

${ }^{*}$ Correlation is significant at the 0.01 level (two-tailed).

Table 5. Relative hydration index with lower cut-off values across seven percentile groups displaying Uvol, Usg, Ucol and TFI from Somaliland women compared with identical hydration indices (Ref.) from Armstrong et al. ${ }^{(4)}$

\begin{tabular}{|c|c|c|c|c|c|c|c|c|c|c|c|}
\hline \multirow[b]{3}{*}{ Group } & \multirow[b]{3}{*}{ Percentile } & \multirow{3}{*}{$\begin{array}{l}\text { Hydration categories } \\
\text { Ref. }\end{array}$} & \multicolumn{9}{|c|}{ Lower cut-off for hydration groups } \\
\hline & & & \multirow{2}{*}{$\begin{array}{l}\text { Uosm } \\
\text { Ref. }\end{array}$} & \multicolumn{2}{|c|}{ Uvol (litres) } & \multicolumn{2}{|c|}{ Usg } & \multicolumn{2}{|c|}{ Ucol } & \multicolumn{2}{|c|}{ TFI (litres) } \\
\hline & & & & Ref. & S. land & Ref. & S. land & Ref. & S. land & Ref. & S. land \\
\hline 7 & $91-100$ & & 320 & $2 \cdot 07$ & $2 \cdot 22$ & $<1.008$ & 1.007 & $<3$ & $<2 \cdot 1$ & $2 \cdot 80$ & $2 \cdot 83$ \\
\hline 6 & $76-90$ & Hyperhydration & 382 & 1.83 & 1.67 & 1.008 & 1.009 & 3 & $2 \cdot 6$ & 2.47 & $2 \cdot 42$ \\
\hline 5 & $61-75$ & & 548 & $1 \cdot 24$ & $1 \cdot 30$ & 1.012 & 1.010 & 4 & 3.3 & 1.83 & 2.09 \\
\hline 4 & $40-60$ & Euhydration & 705 & 0.95 & 1.05 & $1 \cdot 016$ & 1.012 & 5 & 3.9 & $1 \cdot 30$ & 1.88 \\
\hline 3 & 25-39 & & 809 & 0.83 & 0.84 & $1 \cdot 021$ & 1.014 & 5 & $4 \cdot 6$ & $1 \cdot 15$ & 1.68 \\
\hline 2 & $10-24$ & Hypohydration & 863 & 0.53 & 0.59 & 1.024 & 1.018 & 6 & $5 \cdot 0$ & 0.95 & 1.35 \\
\hline 1 & $0-9$ & & $>863$ & $<0.53$ & $<0.59$ & 1.026 & $>1.018$ & $>6$ & $>5.0$ & $<0.95$ & $<1.35$ \\
\hline
\end{tabular}




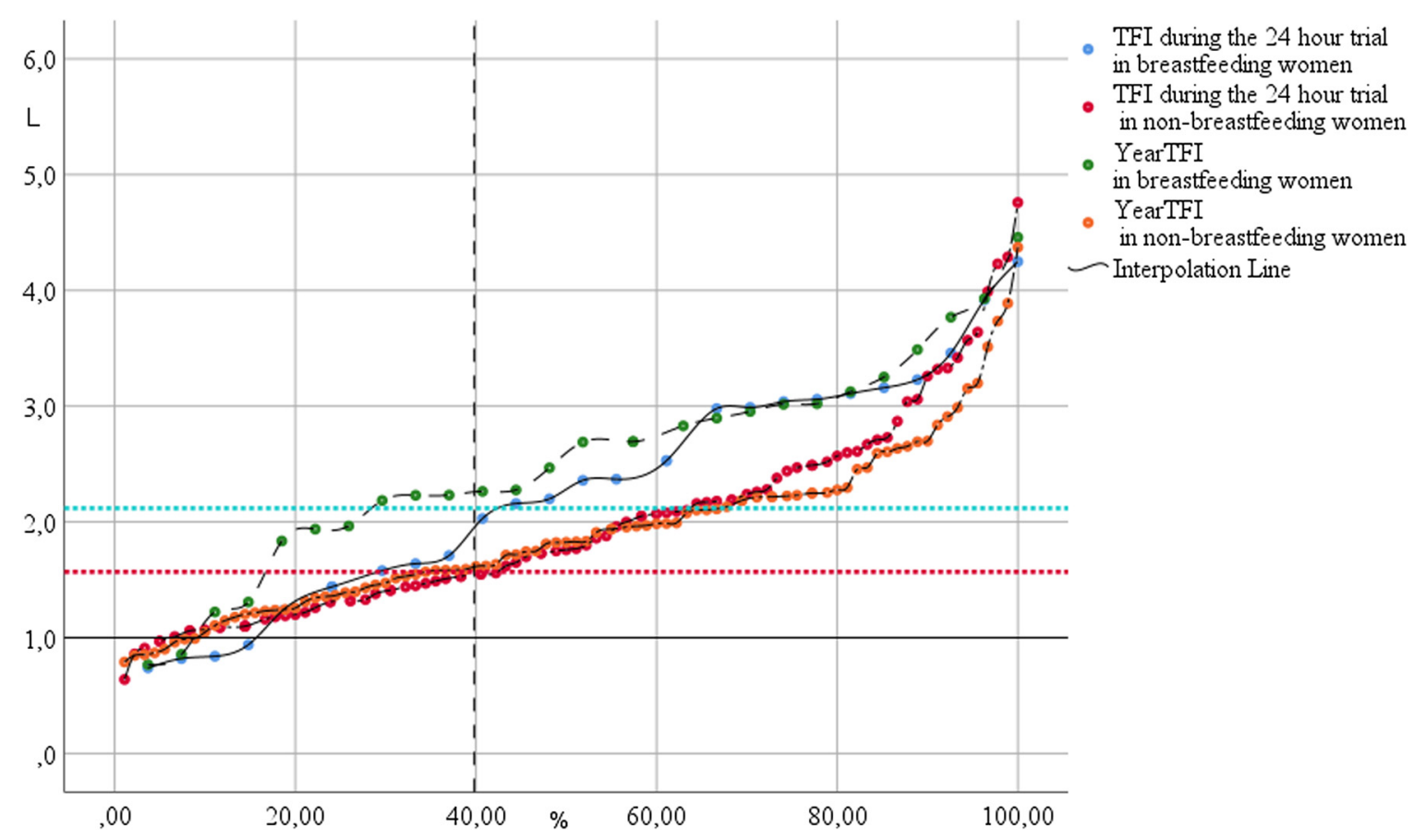

Fig. 2. Overlay scatterplot of individual total fluid intake in litre ( $y$-axis) split into breast-feeding and non-breast-feeding women. Percentiles on the $x$-axis. The two horizontal lines indicate the combined 40 percentile cut-off values of the $24 \mathrm{~h}$ trial (TFI) and estimates from the whole year (yearTFI) in non-pregnant, non-breast-feeding and breast-feeding women.

completeness and accuracy of data collection thoroughly. The use of urine collected through $24 \mathrm{~h}$ avoids coincidental fluctuation in hydration and is more reliable than spot urine measures ${ }^{(35)}$. The recruitment base for the women was broad, and the background characteristics of the non-completers did not differ significantly from the completers.

\section{Fluid intake}

In non-pregnant, non-breast-feeding women from urban Somaliland, we found a mean TFI of 1.98 litres. A recent systematic literature review of TFI presents fifteen populations of adult females from Europe, China and the Americas with a mean TFI range of 1.05-2.89 litres, six of them above 2.0 litres ${ }^{(7)}$. A female Indonesian sample had a mean TFI of 2.76 litres $^{(36)}$. In our study, TFI in lactating women was 2.29 litres, while French lactating women had a TFI of $2 \cdot 10$ litres ${ }^{(37)}$. Comparatively, the TFI of Somaliland women is quite modest. In multivariate regression, only weight remained significantly associated with TFI, as has been found elsewhere $^{(19)}$.

Mean PWI was just below $50 \%$ of TFI with a mean volume of 1.0 litre. Compared with the mean range of $0 \cdot 5-2 \cdot 0$ litres from the twelve relevant studies in the review, Somaliland women are found in the middle, including the ratio ${ }^{(7)}$. However, a median PWI of 0.63 litre - less than three servings per day - leaves a small free water reserve to protect against dehydration on hot and active days, and we recommend that these women exchange some of their beverages for plain water.

A median of 2.5 cups a day of Somali tea is in line with previous findings from the country ${ }^{(27)}$. In the review, seven
European countries have documented female tea/coffee intake of around half a litre ${ }^{(7)}$.

Fresh dairy products are in little use; $75 \%$ of the women are drinking an average of $27 \mathrm{ml}$ or less per day. When including powder milk, the volume is $63 \mathrm{ml}$ or less, not accounting for what is usually mixed in the tea. A similar situation can be seen with fresh fruit juices: the majority have one serving only twice a month or less. In various European populations, these beverage intakes are three to ten times higher ${ }^{(7)}$. Milk and fresh fruits usually have a high content of micronutrients, and the women would have benefitted from a higher intake, although cost might be a challenge. We believe the female nomadic population has a higher intake of fresh milk.

\section{Hydration biomarker correlation}

The correlation matrix describes coherence between reporting (yearTFI, $24 \mathrm{~h}$ urine units) and reality (TFI, Uvol) during the trial in the life of these women. The moderate correlation between yearTFI and TFI is reasonable, with expected day-to-day and seasonal variations in TFI and typical recall bias in the BFQ. Twenty-four hour urine units showed the strongest correlation with TFI $(r$ 0.67) and Uvol $(r$ 0.87). Our findings are interesting, since measurement only requires the sum of magnitude of voids during $24 \mathrm{~h}$. The same strategy has recently been used for assessing Ucol directly in lavatories ${ }^{(38)}$, and the number of voids is used to assess hydration ${ }^{(5,14,39)}$. In this population, $24 \mathrm{~h}$ urine units could be used as an easy proxy for Uvol when volume scaling of urine metabolites is necessary, one urine unit (small void) equalling $124 \mathrm{ml}$ of urine. No urine hydration biomarker was well suited to predict TFI. 


\section{Hydration status}

Hydration might be difficult to assess ${ }^{(12)}$. Uvol, Usg and Ucol are all biomarkers able to distinguish euhydration from hypohydration and mild dehydration, but accurate interpretation is context-dependent ${ }^{(8,12,21)}$. In this study, $24 \mathrm{~h}$ Uvol, Usg, Ucol and TFI represent operational biomarkers available and replicable in field work and low resource contexts ${ }^{(8,21,40)}$. Since Usg measures the weight of particles dissolved, and Uosm measures the number (mol), variation in the relative concentration of particles with large (protein, glucose and urea) and small $\left(\mathrm{Na}^{+}, \mathrm{K}^{+}\right.$and $\left.\mathrm{Cl}^{-}\right)$molecular weights will affect cut-off levels of Usg relative to Uosm ${ }^{(41-43)}$. Nevertheless, studies have shown a strong correlation between the two in adults ( $r$ 0.94-0.99) with refractometry ${ }^{(42,44)}$, less so with dipstick

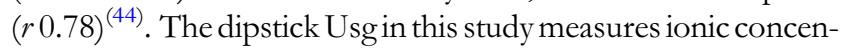
tration. In healthy adults, protein fluctuations are only affecting measurements when the proteins are charged: $\mathrm{pH}$ biases the readings in a fairly linear manner, but is not systematically adjusted for in the readings of most dipsticks. Since the development usually is based on regression lines with refractometry, and individual deviation from gold standard can be high, the Usg values works better to evaluate groups than individuals ${ }^{(41)}$. In our study, a sensitivity analysis excluding urines with $\mathrm{pH} 7$ did not alter the results, and proteinuria was not a problem.

The characteristic Ucol is mainly caused by the yellow pigment urobilin. The concentration of urobilin in urine is not only determined by hydration, but also by the type of microflora in the gut and the total amount of degraded haeme, of which $\mathrm{Hb}$ constitutes $80-85 \%{ }^{(45,46)}$. Visual Ucol assessment can be biased by individual colour and light perceptions, light conditions, size and depth of urine containers, flavonoids from food, food dyes and drugs ${ }^{(16,43,47)}$. Despite this, Ucol has been shown to correlate strongly with Uosm in several studies $(r 0 \cdot 62-0 \cdot 88)^{(4,11,16,39)}$. We did not find any association between strong coloured food items and atypical Ucol in our study.

A relationship between locally available hydration biomarkers has been established in this study. We decided to use the means of hydration percentile groups as a basis for the hydration indices, reducing the impact of methodological challenges and individual variability in the biomarkers of choice. We sorted individuals into the different percentile groups based on Uvol, the only urine ratio variable. The percentile groups were wider towards the median in order to model a typical population distribution, corresponding to a similar display made by Armstrong et al. ${ }^{(4)}$. In this way, we were also able to make a relative comparison between a Western, well characterised female hydration sample and our novel study from the Horn of Africa.

Using Uvol as a contrast, Somaliland women in this study have relatively higher TFI and their urine is more diluted than the US women. A higher TFI is reasonable due to heat-related water losses, although we do not have any meteorological data for comparison. There are several explanations for the comparatively less concentrated urine apart from the methodological issues. Somaliland women might have less solutes to excrete ${ }^{(1)}$. A likely candidate is urea due to low protein intake, as has been shown in several African populations and a micronutrient study from Somaliland ${ }^{(27,48)}$. The low dairy intake does not improve protein intake in this population. Somaliland women might also have less haeme to excrete due to a consistent low $\mathrm{Hb}$ in the female, fertile population with a national mean of $7.4 \mathrm{mmol} / 1$ measured in $2009^{(27)}$. We are not aware of any studies that have investigated the theoretical correlation between $\mathrm{Hb}$ and Ucol values.

With these uncertainties in mind, we have estimated the number of dehydrated individuals to $5 \%$ and a further $35 \%$ as hypohydrated. Comparatively, in two female populations from Europe and US, 19 and 9\% were classified as dehydrated, respectively ${ }^{(3,4)}$. In US NHANES 2009-2012, more than $70 \%$ were hypohydrated or dehydrated ${ }^{(19)}$. One explanation for the low dehydration level in our study might be the high availability of drinking water, which was better than we had expected. This applies to the city of Hargeisa, but should not be extrapolated to other areas of Somaliland. Another contributing factor might be the habitual high intake of Somali tea.

Using the hydration indices table, we estimated a minimum daily TFI for euhydration in this population to be $1.55-1.77$ litres for non-breast-feeding women, increasing to $2 \cdot 07-2 \cdot 27$ litres for breast-feeding women. The widespread mixed breastfeeding habits might explain the low additional TFI of $0 \cdot 5$ litre $^{(49)}$.

There are some limitations to this study. Although the correlation matrix shows strong relationships between hydration biomarkers collected with different tools, these tools are not validated towards gold standards of Uosm and $7 \mathrm{~d}$ drinking diaries with direct volume measurements. The $24 \mathrm{~h}$ trial happened right after the rainy season, and this might have improved the availability of water and other beverages. Finally, we cannot claim that the sample is fully representative for women in Hargeisa, and the findings should not be generalised to other parts of the country or to diseased women.

\section{Conclusions}

This article is contributing to the validation of hydration indices in a healthy, African female population with context, drinking habits, cuisine and nutrient intake different from typical populations from which current international guidelines of fluid intake and hydration have been developed. In this mixed population of non-pregnant women, TFI and PWI are comparable to a number of European populations. Intakes of fresh dairy and fruit products are almost negligible with large distributional differences. Twenty-four hour urine units is a promising variable for urine volume scaling. Assessing hydration with urine units, dipstick Usg and Ucol have good discriminatory ability at the group level and could be explored at the individual level with sensitivity and specificity against Uosm in a future study. We estimated $60 \%$ of the women to be above the euhydration lower cut-off when using the total information in the hydration biomarker indices. Forty percent hypo- and dehydrated women are less than findings from several Western countries, and less than we had expected. The adjacent euhydration cut-off levels for TFI, 
Uvol and urine units can be used as a guide at the population level in similar climatic and dietary conditions. With the growing knowledge of long-term health risks, not only in dehydration, but also in habitual hypohydration, Somaliland women should be encouraged to a higher TFI and, especially, PWI. The findings are practically relevant to the health system, public health authorities and NGOs involved in nutrition and water provision in Somaliland.

\section{Supplementary material}

The supplementary material for this article can be found at https://doi.org/10.1017/jns.2021.54.

\section{Acknowledgments}

We are indebted to the research staff Filsan $\mathrm{H}$. Mohamed, Zuhuur M. Abdi, Qabuul A. Abdi, Nimo J. Ali, Rahma M. Absiiye, Hamda O. Ali, Fathia Akli, Asia A. Abdilahi and Barkhad J. Dagaal for their dedication and hard work. The Dean of medical faculty, Dr. Deria Ereg, facilitated the piloting. We thank Prof. Lawrence E. Armstrong (University of Connecticut), Prof. Sven G. Hinderaker and $\mathrm{PhD}$ Øystein E. Olsen (University of Bergen) for technical input. Without the eager support of the leaders of NNM, NAGAAD women umbrella Somaliland, Hargeisa Voluntary Youth Committee (HAWOYOCO), Somaliland Women Organization (SOLWO), TAWAKAL in M. Mooge, Iftiin $\mathrm{MCH}$ and Edna Adan University Hospital MCH, the project would never have succeeded.

This work has been supported by two grants from the Norwegian Agency for Development Cooperation (Norad/ Digni) (E.H., A.A.Y. and M.R. grant ID 'CBH: NORAD QZA-12/0763-101' and 'Finalizing research: Digni. Knowledge development fund 23.04.19').

E.H. contributed to all parts of the study from conception until final approval. A.A.Y. contributed to the design, acquisition and interpretation of data and revision of the manuscript, including final approval. A.A.M. contributed to the conception and design, analysis and interpretation of data and revision of the manuscript, including final approval. M.R. contributed to the design, analysis and interpretation of data and revision of the manuscript, including final approval.

This study was conducted according to the guidelines laid down in the WMA Declaration of Helsinki, and all procedures involving research study participants were approved by the Ministry of Health in Somaliland on 11 January 2011. Ethical clearance (No. 2010/1905/REK sør-øst A) was also given by the Norwegian Regional Ethical Committee (REK Øst) on 15 September 2010 and extended until 2022. Written or verbal informed consent was obtained from all research subjects. Verbal consent was witnessed and formally recorded.

The authors declare that they have no conflicts of interest.

\section{References}

1. Manz F \& Wentz A (2003) 24-h hydration status: parameters, epidemiology and recommendations. Eur J Clin Nutr 57, S10-S18.
2. Cheuvront SN \& Kenefick RW (2016) Am I drinking enough? Yes, no, and maybe. J Am Coll Nutr 35, 185-192.

3. Malisova O, Athanasatou A, Pepa A, et al. (2016) Water intake and hydration indices in healthy European adults: the European Hydration Research Study (EHRS). Nutrients 8, 204.

4. Armstrong LE, Johnson EC, Munoz CX, et al. (2012) Hydration biomarkers and dietary fluid consumption of women. J Acad Nutr Diet 112, 1056-1061.

5. Armstrong LE \& Johnson EC (2018) Water intake, water balance, and the elusive daily water requirement. Nutrients 10, 1928.

6. Sawka MN, Cheuvront SN \& Carter R (2005) Human water needs. Nutr Rev 63, S30-S39.

7. Ozen AE, Bibiloni Mdel M, Pons A, et al. (2015) Fluid intake from beverages across age groups: a systematic review. J Hum Nutr Diet 28, 417-442.

8. Perrier E, Rondeau P, Poupin M, et al. (2013) Relation between urinary hydration biomarkers and total fluid intake in healthy adults. Eur J Clin Nutr 67, 939-943.

9. Institute of Medicine (2005) Dietary Reference Intakes for Water, Potassium, Sodium, Chloride, and Sulfate, Reference Intakes for Electrolytes and Water. Washington, DC, USA: National Academy Press.

10. EFSA Panel on Dietic Products Nutrition and Allergies (NDA) (2010) Scientific opinion on dietary reference values for water. EFS A J 8, 1459-1507.

11. McKenzie AL, Muñoz CX, Ellis LA, et al. (2017) Urine color as an indicator of urine concentration in pregnant and lactating women. Eur J Nutr 56, 355-362.

12. Perrier ET (2017) Shifting focus: from hydration for performance to hydration for health. Ann Nutr Metab 70, 4-12.

13. Perrier ET, Buendia-Jimenez I, Vecchio M, et al. (2015) Twenty-four-hour urine osmolality as a physiological index of adequate water intake. Dis Markers 2015, 231063.

14. Perrier ET, Armstrong LE, Bottin JH, et al. (2020) Hydration for health hypothesis: a narrative review of supporting evidence. Eur J Nutr 60, 1167-1180.

15. Sawka MN, Burke LM, Eichner ER, et al. (2007) American college of sports medicine position stand. Exercise and fluid replacement. Med Sci Sports Exerc 39, 377-390.

16. Belasco R, Edwards T, Munoz AJ, et al. (2020) The effect of hydration on urine color objectively evaluated in CIE $1(*) \mathrm{a}(*) \mathrm{b}\left({ }^{*}\right)$ color space. Front Nutr 7, 576974.

17. Perrier ET, Bottin JH, Vecchio M, et al. (2017) Criterion values for urine-specific gravity and urine color representing adequate water intake in healthy adults. Eur J Clin Nutr 71, 561-563.

18. Armstrong LE, Munoz CX \& Armstrong EM (2020) Distinguishing low and high water consumers: a paradigm of disease risk. Nutrients 12,858.

19. Stookey JD (2019) Analysis of 2009-2012 Nutrition Health and Examination Survey (NHANES) data to estimate the median water intake associated with meeting hydration criteria for individuals aged 12-80 in the US population. Nutrients 11, 657.

20. Popkin BM, D'Anci KE \& Rosenberg IH (2010) Water, hydration, and health. Nutr Rev 68, 439-458.

21. Baron S, Courbebaisse M, Lepicard EM, et al. (2015) Assessment of hydration status in a large population. Br J Nutr 113, 147-158.

22. Berg RC, Underland V, Odgaard-Jensen J, et al. (2014) Effects of female genital cutting on physical health outcomes: a systematic review and meta-analysis. BMJ Open 4, e006316.

23. Heen E \& Madar AA (2020) Bottled water from national manufacturers in Somaliland: water quality and health implications. ScienceOpen Preprints, DOI: 10.14293/S2199-1006.1.SOR-. PPRWQPU.v1.

24. SWALIM (2012) Hydrogeological Survey and Assessment of Seletced Areas in Somaliland and Puntland. Technical Report No. W-20, FAO-SWALIM (GCP/SOM/049/EC) Project. Nairobi, Kenya.

25. UNICEF Somalia (2011) Multi Indicator Cluster Survey (MICS) 4, Somaliland. Nairobi: UNICEF.

26. UNICEF Somalia (2006) Multiple Indicator Cluster Survey (MICS 3) Somalia. Nairobi: UNICEF. 
27. Kassim IAR, Seal A, Moloney G (2010) National Micronutrient and Anthropometric Nutrition Survey Somalia 2009. Nairobi: FSNAU, UNICEF, WHO, WFP, CIHD.

28. Canaris GJ, Manowitz NR, Mayor G, et al. (2000) The Colorado thyroid disease prevalence study. Arch Intern Med 160, 526-534.

29. Norwegian Mother and Child Cohort Study (MoBa) (2011) https:// www.fhi.no/en/studies/moba/for-forskere-artikler/questionnairesfrom-moba/ (accessed 30 June 2021).

30. Report of a WHO Expert committee (1995) Physical Status: The Use and Interpretation of Anthropometry. WHO Technical Report Series No. 854. Geneva.

31. Gandy J, Martinez H, Guelinckx I, et al. (2016) Relevance of assessment methods for fluid intake. Ann Nutr Metab 68, 1-5.

32. Ulijaszek SJ \& Kerr DA (1999) Anthropometric measurement error and the assessment of nutritional status. Br J Nutr 82, 165-177.

33. Armstrong LE, Maresh CM, Castellani JW, et al. (1994) Urinary indices of hydration status. Int J Sport Nutr 4, 265-279.

34. FitzGerald MP, Stablein U \& Brubaker L (2002) Urinary habits among asymptomatic women. Am J Obstet Gynecol 187, 1384-1388.

35. Athanasatou A, Kandyliari A, Malisova O, et al. (2019) Fluctuation of water intake and of hydration indices during the day in a sample of healthy Greek adults. Nutrients 11, 793.

36. Laksmi PW, Morin C, Gandy J, et al. (2018) Fluid intake of children, adolescents and adults in Indonesia: results of the 2016 Liq.In ${ }^{7}$ national cross-sectional survey. Eur J Nutr 57, 89-100.

37. McKenzie AL, Perrier ET, Guelinckx I, et al. (2017) Relationships between hydration biomarkers and total fluid intake in pregnant and lactating women. Eur J Nutr 56, 2161-2170.

38. Wardenaar FC, Thompsett D, Vento KA, et al. (2021) A lavatory urine color (LUC) chart method can identify hypohydration in a physically active population. Eur J Nutr 60, 2795-2805.
39. Adams JD, Arnaoutis G, Johnson EC, et al. (2021) Combining urine color and void number to assess hydration in adults and children. Eur J Clin Nutr, https://doi.org/10.1038/s41430-02000834-w.

40. Armstrong LE (2007) Assessing hydration status, the elusive gold standard. J Am Coll Nutr 26 (5 suppl), 575S-584S.

41. Chadha V, Garg U \& Alon US (2001) Measurement of urinary concentration: a critical appraisal of methodologies. Pediatr Nephrol 16, 374-382.

42. Leech S \& Penney MD (1987) Correlation of specific gravity and osmolality of urine in neonates and adults. Arch Dis Child 62, 671-673.

43. Simerville JA, Maxted WC \& Pahira JJ (2005) Urinalysis: a comprehensive review. Am Fam Physician 71, 1153-1162.

44. Roessingh AS dB, Drukker A \& Guignard JP (2001) Dipstick measurements of urine specific gravity are unreliable. Arch Dis Child 85, 155-157.

45. Sampson DL, Chng YL, Upton Z, et al. (2013) The highly abundant urinary metabolite urobilin interferes with the bicinchoninic acid assay. Anal Biochem 442, 110-117.

46. Kalakonda A, Jenkins BA, John S (2020) Physiology, Bilirubin. In StatPearls. Treasure Island (FL): StatPearls Publishing. https:// www.ncbi.nlm.nih.gov/books/NBK470290/

47. Ellis LA, Yates BA, McKenzie AL, et al. (2016) Effects of three oral nutritional supplements on human hydration indices. Int J Sport Nutr Exerc Metab 26, 356-362.

48. Schonfeldt HC \& Gibson Hall N (2012) Dietary protein quality and malnutrition in Africa. Br J Nutr 108, S69-S76.

49. Lundeby KM, Heen E, Mosa M, et al. (2020) Neonatal morbidity and mortality in Hargeisa, Somaliland: an observational, hospital based study. Pan Afr Med J 37, 3. 